\title{
Esquemas terapêuticos para combate da Covid-19: revisão sistemática
}

\author{
Therapeutic schemes to combat Covid-19: systematic review \\ Esquemas terapéuticos para combatir Covid-19: revisión sistemática
}

Recebido: 28/12/2020 | Revisado: 03/01/2021 | Aceito: 07/01/2021 | Publicado: 08/01/2021

Danielli Marinho Zuil

ORCID: https://orcid.org/0000-0003-0020-6781 Universidade Federal do Maranhão, Brasil E-mail: danielibaeza@hotmail.com Volmar Morais Fontoura

ORCID: https://orcid.org/0000-0001-8731-6750 Universidade Estadual do Tocantins, Brasil E-mail: volmar_morais@hotmail.com Floriacy Stabnow Santos ORCID: https://orcid.org/0000-0001-9875-2283 Universidade Federal do Maranhão, Brasil E-mail: floriacys@gmail.com Marcelino Santos Neto

ORCID: https://orcid.org/0000-0002-6105-1886 Universidade Federal do Maranhão, Brasil E-mail: marcelinosn@gmail.com Lívia Maia Pascoal

ORCID: https://orcid.org/0000-0003-0876-3996 Universidade Federal do Maranhão, Brasil E-mail: livia_mp@hotmail.com

Márcia Caroline Nascimento Sá Ewerton Martins

ORCID: https://orcid.org/0000-0001-5678-6047 Universidade Federal do Maranhão, Brasil E-mail: marcia.caroline@ufma.br Maikon Graepp Fontoura

ORCID: https://orcid.org/0000-0001-5514-4114 Centro Universitário do Maranhão, Brasil E-mail: maikon2.0@hotmail.com Alzira Regina Dantas Dias ORCID: https://orcid.org/0000-0002-3045-2185 Faculdade Pitágoras, Brasil E-mail: alziradantasdias@gmail.com Cynthia Cardozo Dias Lima ORCID: https://orcid.org/0000-0002-0885-9915 Hospital Regional Materno Infantil de Imperatriz E-mail: cynthiacdias@hotmail.com Iolanda Graepp-Fontoura ORCID: https://orcid.org/0000-0002-9201-480X Universidade Federal do Maranhão, Brasil E-mail: iolanda.graepp@ufma.br

\section{Resumo}

O objetivo deste estudo foi investigar os principais esquemas terapêuticos utilizados até o momento no combate da Covid-19 no cenário mundial. É uma revisão sistemática de literatura realizada nas bases ScienceDirect, Literatura Latino-Americana e do Caribe em Ciências da Saúde (Lilacs) e Scientific Electronic Library Online (SciELO), utilizando o termo "treatment Covid-19", realizada no mês de abril de 2020. Foram selecionados 16 artigos, segundo os critérios de inclusão: artigos de pesquisa, publicados entre fevereiro de 2019 a abril de 2020, sem distinção de idiomas. O trabalho foi organizado de acordo com as recomendações PRISMA, registrado no PROSPERO (CRD42020186262). Os artigos encontrados, variaram de estudos in vitro, in silico, ensaios clínicos abertos, coorte, retrospectivos e analíticos, realizados na China, na França, na Índia, na Arábia Saudita e na Coreia do Sul, com maior número de publicações chinesas (70,5\%). As amostras variaram de uma a 199 pessoas, todas infectadas com o SARSCoV-2, com maior percentual do sexo feminino (51,7\%), idades entre 18 a 88 anos. Medicamentos como lopinavir, ritonavir, favipiravir, arbidol, costicoteroides, hidroxicloroquina, receitas da medicina tradicional chinesa, glicirrizina, azitromicina e tocilizumabe foram analisados nos estudos de forma monoterápica ou associados entre si, assim como transplante de células tronco mesenquimais, troca plasmática intensiva e imunoglobulina intravenosa. Houve divergências e complementação de resultados entre os autores. Apesar de apresentarem descobertas e auxiliarem no combate à pandemia, os estudos apresentam drogas promissoras para o tratamento da sintomatologia e carga viral, com o objetivo de identificar a terapia ideal para a doença, não obtendo consenso.

Palavras-chave: COVID-19; SARS-Cov-2; Manejo clínico; Drogas antivirais. 


\begin{abstract}
The aim of this study was to investigate the main therapeutic regimens used so far in the Covid-19 fight on the world stage. Is a systematic literature review conducted in ScienceDirect, Literatura Latino-Americana e do Caribe em Ciências da Saúde (Lilacs) and Scientific Electronic Library Online (SciELO) databases, using the term "treatment Covid-19", carried out in April 2020. We selected 16 articles according to the inclusion criteria: research articles, published between February 2019 and April 2020, without distinction of languages. The work was organized according to PRISMA recommendations, registered in PROSPERO. The articles found, ranged from in vitro, in silico, open clinical trials, cohort, retrospective and analytical, and were conducted in China, France, India, Saudi Arabia and South Korea, with the highest number of Chinese publications (70.5\%). Samples range from one to 199 people, all infected with the SARS-CoV-2 virus, with a higher percentage of females (51.7\%), ages 18 to 88 years. Medicines like lopinavir, ritonavir, favipiravir, arbidol, costicoteroids, hydroxychloroquine, recipes of traditional Chinese medicine, glycirrizine, azithromycin, and tocilizumab were analyzed in studies in a monotherapeutic or associated form, as well as mesenchyhimsal stem cell transplantation, intensive plasma exchange and intravenous immunoglobulin. There were divergences and complementation of results among the authors. Despite presenting findings and assisting in the fight against the pandemic, current studies present promising drugs for the treatment of symptomatology and viral load, with the objective of identifying an ideal treatment for the disease, not obtaining consensus.
\end{abstract}

Keywords: COVID-19; SARS-CoV-2; Clinical management; Antiviral drugs.

\title{
Resumen
}

El objetivo de este estudio era investigar los principales regímenes terapéuticos utilizados hasta ahora en la lucha contra Covid-19 en la escena mundial. Es una revisión sistemática de la literatura realizada en las bases de datos ScienceDirect, Latin American Literature in Health Sciences (Lilacs) y Scientific Electronic Library Online (SciELO), utilizando el término "tratamiento Covid-19", celebrado en abril de 2020. Seleccionamos 16 artículos según los criterios de inclusión: artículos de investigación, publicados entre febrero de 2019 y abril de 2020, sin distinción de idiomas. El trabajo se organizó de acuerdo con las recomendaciones de prisma, registradas en PROSPERO. Los artículos encontrados iban desde ensayos clínicos in vitro, en silicio, abierto, cohorte, retrospectivo y analítico realizados en China, Francia, India, Arabia Saudita y Corea del Sur, con el mayor número de publicaciones chinas $(70,5 \%)$. Las muestras oscilaron entre una y 199 personas, todas infectadas con SARS-CoV-2, con un mayor porcentaje de mujeres $(51,7 \%)$, de 18 a 88 años. Se analizaron medicamentos como lopinavir, ritonavir, favipiravir, arbidol, costicoteroides, hidroxicloroquina, recetas de medicina tradicional china, glicirina, azitromicina y tocilizumab en estudios en forma monoterapéutica o asociada, así como trasplante de células madre mesénquipales, intercambio plasmático intensivo e inmunoglobulina intravenosa. Hubo divergencias y complementación de los resultados entre los autores. A pesar de presentar los hallazgos y ayudar en la lucha contra la pandemia, los estudios presentan fármacos prometedores para el tratamiento de la sintomatología y la carga viral, con el objetivo de identificar la terapia ideal para la enfermedad, no obtener consenso.

Palabras clave: COVID-19; SARS-CoV-2; Gestión clínica; Medicamentos antivirales.

\section{Introdução}

A doença pelo coronavírus 2019 (Covid-19), responsável pela síndrome respiratória aguda grave 2, espalhou-se rapidamente desde sua origem na cidade de Wuhan, província de Hubei, na China, para o resto do mundo (Lu et al., 2020; Zu et al., 2020). Por conta dessa rápida disseminação, a Organização Mundial da Saúde (OMS), em 11 de março de 2020, denominou a doença como pandemia (Karami et al., 2020; Zu et al., 2020).

A análise do genoma viral revelou que o novo coronavírus é filogeneticamente próximo ao coronavírus da síndrome respiratória aguda grave, que foi agente causador de um surto viral em 2002, compartilhando cerca de $80 \%$ da identidade de sequência (Lu et al., 2020; Zhou et al., 2020). Em função dessas e de outras similaridades, o International Committee on Taxonomy of Viruses e outros virologistas nomearam o vírus como coronavírus da síndrome respiratória aguda grave 2 (SARSCoV-2) (Gorbalenya et al., 2020).

Os coronavírus são envelopados, com sentido positivo, RNA de fita simples (ssRNA+), pertencentes à família Coronaviridae, que recebe esse nome por sua semelhança com uma coroa, quando vista sobre microscopia óptica (Zhou et al., 2020).

A maioria dos coronavírus possui de oito a dez quadros de leituras abertas (ORFs, do inglês open reading frame) (Gorbalenya et al., 2020; Sarzi-Puttini et al., 2020). Uma vez que esses vírus se ligam a receptores celulares de células específicas do corpo de humanos, induzindo sua endocitose, torna-se possível liberar seu material genético no citoplasma dessa célula, que 
prontamente é lido pelos ribossomos, induzindo a síntese de proteínas estruturais e não estruturais, as quais mediarão os processos de transcrição e replicação viral, sem passar por processos de conversão de material genético que outros vírus necessitam e culminando na lise celular e disseminação de novos vírus (Cespedes \& Souza, 2020; Mcintosh \& Bloom, 2020).

O período de incubação da infecção é de 5 a 6 dias, com intervalo que pode durar até 14 dias. O período médio de transmissibilidade dos pacientes infectados é de 7 dias após o início dos sintomas, no entanto pacientes assintomáticos podem transmitir o vírus (Brasil, 2020; Ramos et al., 2020).

O vírus possui alta taxa de transmissibilidade, sabendo-se até agora que a transmissão se dá por gotículas de saliva infectadas, inalação ou contato direto com elas (Epidemiology Working Group for NCIP Epidemic Response, 2020; Guo et al., 2020; Singhal, 2020). Além disso, evidências crescentes apontam para a rota de transmissão fecal-oral (Chan et al., 2020).

A apresentação clínica é inespecífica. Estão entre os sintomas febre, faringalgia, diarreia, fadiga, tosse, mialgia, confusão mental, cefaleia, rinorreia, dor no peito, náuseas, vômitos e dificuldade para respirar (Brasil, 2020; Lu et al., 2020; Teixeira, 2020), que se assemelham a quadros de várias outras complicações, respiratórias ou não, dificultando o diagnóstico imediato.

Para fechar o diagnóstico de Covid-19, é preciso estar pautado em informações clínico-epidemiológicas, teste de reação em cadeia da polimerase com transcrição reversa em tempo real (RT-PCR) e/ou sorologia, quando disponível e validada, além de tomografia computadorizada (TC) de tórax - todos cuidadosamente ponderados. A RT-PCR detecta o ácido nucleico por meio da cultura de tecido, na qual o antígeno, ou seja, o vírus é isolado. O teste imunológico é um teste rápido para detecção de anticorpos, tendo resultado positivo para $\operatorname{IgM} / \operatorname{IgG}$ e maior sensibilidade diagnóstica a partir do sétimo dia após terem iniciados os sintomas. A TC de tórax é assessora na detecção e no gerenciamento precoces das manifestações pulmonares, já que os achados são inespecíficos (Brasil, 2020; Lim et al., 2020; Pfefferle et al., 2020).

A enorme evolução, a adaptação e a disseminação desse vírus (Lu et al., 2020) fazem com que cientistas do mundo inteiro investiguem aspectos de sua replicação e patogênese, tentando encontrar alvos terapêuticos eficazes para seu combate. Medicamentos como lopinavir, ritonavir, arbidol, costicosteroides, cloroquina e seus derivados, agentes antifatores de necrose tumoral alfa (TNF- $\alpha$ ) e muitos outros estão sendo utilizados com grupos de teste, mas ainda não se tem consenso sobre sua eficácia, assim como as pesquisas sobre vacinas (Cao et al., 2020; Elfiky, 2020; Lim et al., 2020).

Os estudos realizados com grupos de teste dessas diversas terapias, cotadas por cientistas como propensas a diminuir os sintomas e a carga viral ou imunizar pessoas ainda não infectadas, induzem a um grande número de publicações simultâneas, desde a descoberta da doença. Assim, há uma certa dificuldade de identificar e acompanhar qual terapia é mais promissora.

Espera-se que este estudo facilite a compreensão e a visualização dos alvos terapêuticos estudados atualmente, identificando-os e comparando-os, de acordo a obtenção de consensos e divergências entre os autores quanto às suas eficiências no combate ao coronavírus.

O objetivo deste estudo foi investigar os principais esquemas terapêuticos utilizados até o momento no combate à Covid19 no cenário mundial.

\section{Metodologia}

Foi realizada uma revisão sistemática de literatura de artigos publicados entre dezembro de 2019 a abril de 2020, para responder à pergunta de pesquisa: Quais os principais esquemas terapêuticos utilizados para o tratamento da Covid-19 atualmente no mundo? Seguiram-se as recomendações Preferred Reporting Items for Systematic Reviews and Meta-Analyses PRISMA (Galvão et al., 2015; Shamseer et al., 2015). Essas recomendações consistem em um checklist com 27 itens disponíveis neste artigo em anexo (Tabela 1) e um fluxograma com quatro etapas: identificação, seleção, elegibilidade e inclusão, que tem como objetivo ajudar os autores a melhorar o relato de revisões sistemáticas (PRISMA). Esta pesquisa foi registrada no PROSPERO 
(número de registro: CRD42020186262), para ajudar a minimizar o risco de viés (Shamseer et al., 2015). Os autores do estudo foram contactados por $e$-mail para obter mais informações sobre as pesquisas.

Tabela 1. Lista de verificação do PRISMA

\begin{tabular}{|c|c|c|}
\hline Seção/tópico & Item da lista de verificação & $\begin{array}{l}\text { Número das } \\
\text { linhas }\end{array}$ \\
\hline Identificação & O artigo foi identificado como um protocolo de revisão sistemática & $1-3$ \\
\hline Registo & $\begin{array}{l}\text { Foi registrado, forneça o nome do registro e o número de inscrição no } \\
\text { Resumo }\end{array}$ & 55 \\
\hline Contato & $\begin{array}{l}\text { Fornecidos o nome, a afiliação institucional e o endereço de } e \text {-mail de } \\
\text { todos os autores do protocolo; fornecido endereço de } e \text {-mail físico do } \\
\text { autor correspondente }\end{array}$ & 44 \\
\hline Contribuições & $\begin{array}{l}\text { Descritas as contribuições de autores do protocolo e identifique o } \\
\text { fiador da revisão }\end{array}$ & $210-211$ \\
\hline Fontes & Não teve fontes financeiras ou outros suportes para a revisão & $213-214$ \\
\hline Lógica & Descrito a lógica da revisão no contexto do que já se sabe & 185 \\
\hline Objetivos & $\begin{array}{l}\text { Fornecido uma declaração explícita das perguntas que a revisão } \\
\text { abordou com referência aos participantes, intervenções, comparadores } \\
\text { e resultados }\end{array}$ & $181-182$ \\
\hline $\begin{array}{l}\text { Critérios de } \\
\text { elegibilidade }\end{array}$ & $\begin{array}{l}\text { Especado as características do estudo e características do relatório a } \\
\text { serem utilizados como critérios de elegibilidade para a revisão }\end{array}$ & 210 \\
\hline Fontes de informação & $\begin{array}{l}\text { Descrito todas as fontes de informação pretendidas (por exemplo, } \\
\text { bancos de dados eletrônicos, contato com autores de estudos, registros } \\
\text { de ensaios ou outras fontes de literatura cinzenta) com datas planejadas } \\
\text { de cobertura }\end{array}$ & $191-194$ \\
\hline Estratégia de pesquisa & $\begin{array}{l}\text { Apresentado rascunho da estratégia de pesquisa usada para pelo menos } \\
\text { um banco de dados eletrônico, incluindo limites planejados, de tal } \\
\text { forma que pudesse ser repetido }\end{array}$ & $196-199$ \\
\hline Gestão de dados & $\begin{array}{l}\text { Descrito os mecanismos que foram usados para gerenciar registros e } \\
\text { dados ao longo da revisão }\end{array}$ & $201-204$ \\
\hline Processo seletivo & $\begin{array}{l}\text { Declarado o processo que utilizado para a seleção de estudos através } \\
\text { de cada fase da revisão }\end{array}$ & $207-214$ \\
\hline $\begin{array}{l}\text { Processo de coleta de } \\
\text { dados }\end{array}$ & $\begin{array}{l}\text { Descrito o método planejado de extração de dados de relatórios (por } \\
\text { exemplo, formulários de pilotagem, feitos de forma independente, em } \\
\text { duplicata), quaisquer processos de obtenção e confirmação de dados } \\
\text { dos investigadores }\end{array}$ & $216-217$ \\
\hline Itens de dados & $\begin{array}{l}\text { Listado e definido todas as variáveis para as quais foram procurados } \\
\text { dados, quaisquer suposições e simplificações de dados pré-planejadas }\end{array}$ & $201-204$ \\
\hline $\begin{array}{l}\text { Resultados e } \\
\text { priorização }\end{array}$ & $\begin{array}{l}\text { Listado e definido todos os resultados para os quais foram buscados } \\
\text { dados, incluindo priorização dos principais e adicionais resultados, } \\
\text { com fundamentação }\end{array}$ & 230 \\
\hline $\begin{array}{l}\text { Risco de viés em } \\
\text { estudos individuais }\end{array}$ & $\begin{array}{l}\text { Descritos métodos antecipados para avaliar o risco de viés de estudos } \\
\text { individuais, incluindo se isso foi feito no nível de resultado ou estudo, } \\
\text { ou ambos; afirmado como essas informações foram usadas na síntese } \\
\text { de dados }\end{array}$ & $188-189$ \\
\hline \multirow[t]{3}{*}{ Síntese } & $\begin{array}{l}\text { Descrito os critérios sob os quais os dados do estudo foram } \\
\text { sintetizados quantitativamente }\end{array}$ & $216-217$ \\
\hline & $\begin{array}{l}\text { Os dados foram apropriados para a síntese quantitativa e descrito } \\
\text { medidas sumárias planejadas, métodos de manipulação de dados e } \\
\text { métodos de combinação de dados de estudos, incluindo qualquer } \\
\text { exploração planejada de consistência }\end{array}$ & 224 \\
\hline & Descrito quaisquer análises adicionais propostas & - \\
\hline Meta-viés(s) & Especificada avaliação planejada de meta-viés(es) & 227 \\
\hline $\begin{array}{l}\text { Confiança em } \\
\text { evidências cumulativas }\end{array}$ & Descrito como a força do corpo de evidências foi avaliada & - \\
\hline
\end{tabular}

Fonte: Autores. 
A pesquisa bibliográfica foi feita dentre artigos disponíveis nas plataformas PubMed®, Literatura Latino-Americana e do Caribe em Ciências da Saúde (Lilacs) e Scientific Electronic Library Online (SciELO) e ScienceDirect, conforme os descritores MeSH disponíveis (https://www.ncbi.nim.nih.gov/mesh) "treatment COVID-19” (Figura 1).

Figura 1. Termos usados para pesquisa no PubMed®, no Scientific Electronic Library Online (SciELO), na Literatura LatinoAmericana e do Caribe em Ciências da Saúde (Lilacs) e no ScienceDirect.

\begin{tabular}{l}
\hline "therapy"[Subheading] OR "therapy"[All Fields] OR "treatment" [All Fields] OR \\
"therapeutics" [MeSH Terms] OR "therapeutics" [A1l Fields]) AND ("severe acute respiratory \\
syndrome coronavirus 2" [Supplementary Concept] OR "severe acute respiratory syndrome \\
coronavirus 2" [All Fields] OR "ncov"[A1l Fields] OR " 2019-nCoV"[All Fields] OR \\
"COVID-19" [All Fields] OR "SARS-CoV-2"[All Fields] OR ((coronavirus[All Fields] OR \\
"cov"[All Fields]) AND 2019/11[PubDate] : 3000[PubDate]))
\end{tabular}

Fonte: Autores (2020).

As variáveis pesquisadas nos artigos tiveram seus desfechos voltados a: identificação do autor, ano de publicação, país e local do estudo, período do estudo, sexo, idade, desenho de estudo, terapia, objetivos, abordagens e principais conclusões dos autores. Não houve restrição por tipo de idioma.

Os cálculos efetuados para extração de porcentagens e médias de intervalos ou não, foram baseados em fórmulas estatísticas matemáticas.

Foram encontrados 360 no ScienceDirect, 63 trabalhos no PubMed®, nove na Lilacs e dois na SciELO, perfazendo um total de 434. Foram excluídos 340 artigos pelo título e/ou abstract e escopo diferente do assunto escolhido. Foram incluídos 94 trabalhos para avaliar sua elegibilidade, que foram lidos na íntegra, com extração dos dados feita por um autor e verificada por outro autor, chegando a um consenso entre ambos ou de um terceiro. Excluíram-se, ainda, 78 artigos por terem dados incompletos sobre o tratamento e/ou não corresponderem à síntese qualitativa, resultando em 16 artigos para análise sistemática de acordo a Figura 2. Não teve fontes financeiras ou outros suportes para a revisão. 
Figura 2. Fluxograma da seleção dos artigos.

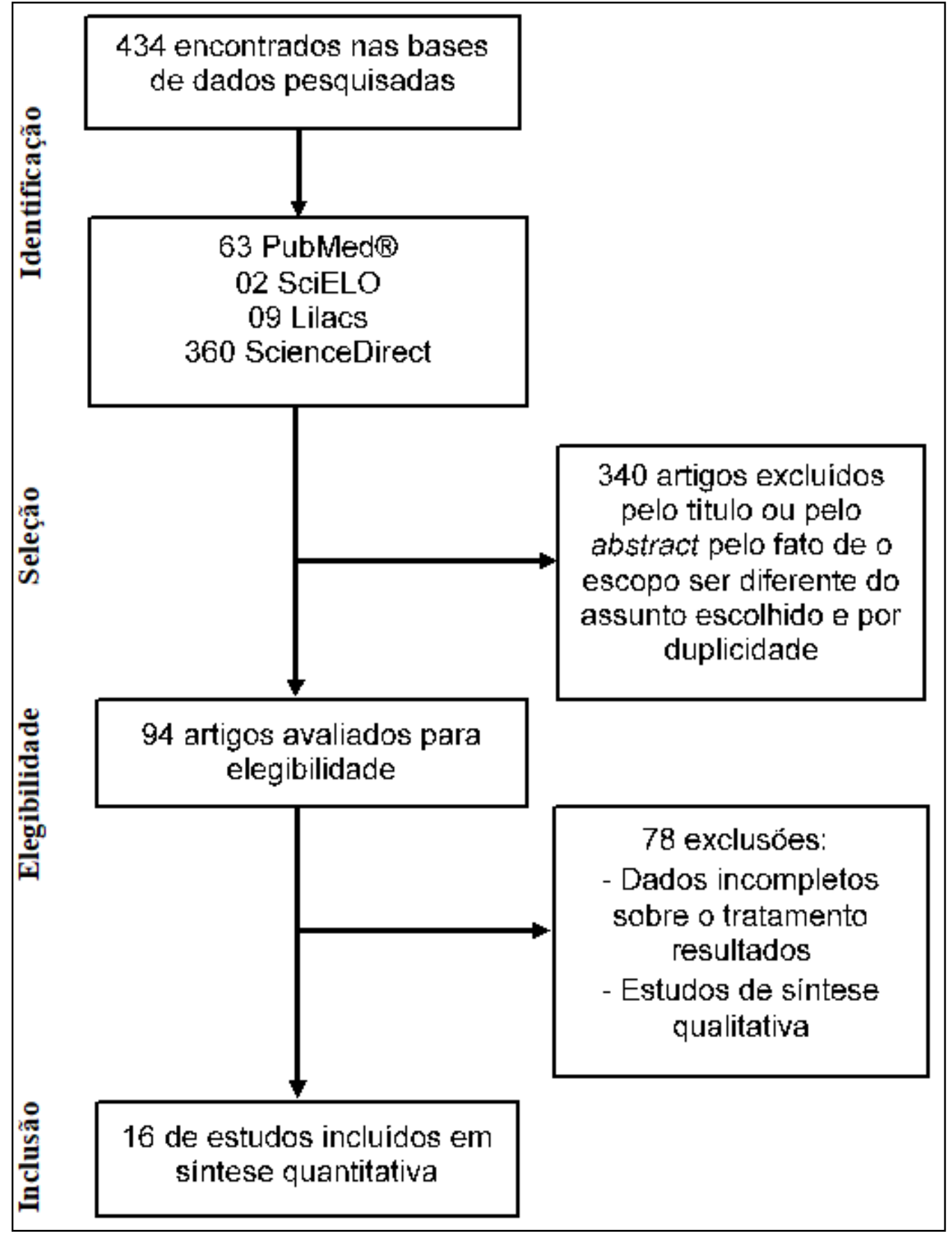

Fonte: SciELO: Scientific Electronic Library Online; Lilacs: Literatura Latino-Americana e do Caribe em Ciências da Saúde.

Foram incluídos todos os artigos que tratavam do tratamento da Covid-19 independente do desenho de estudo, se coorte ou não, comparativos de dois grupos ou não, retrospectivos e descritivos. Foram excluídos os resultados de artigos que não faziam a pesquisa de tratamento.

Possíveis relações entre os estudos inclusos, dispostos em tabelas, foram aclaradas no decorrer do texto, explicando tanto suas características como revisitando dados sobre o tratamento da Covid-19. Foram seguidas orientações e diretrizes preconizadas pelo checklist do PRISMA. Não foi possível realizar metanálise, em virtude da heterogeneidade das informações encontradas e da incompletude dos dados. 


\section{Resultados}

Foram selecionados 16 artigos para síntese qualitativa. Os estudos foram realizados em cinco países diferentes, sendo a maioria (11; 69\%) na China (identificação dos artigos - ID: 1, 2, 3, 8, 9, 10,11,13, 14, 15 e 16), seguida pela França (2; 13\%) (ID: 5 e 6), Coréia do Sul (1; 6\%) (ID: 7), Índia (1;6\%) (ID: 12) e Arábia Saudita (1;6\%) (ID: 4), envolvendo diferentes terapias medicamentosas como forma de alívio e/ou diminuição da carga viral, de modo a formular suas eficácias. Os estudos encontrados foram publicados no período de fevereiro a abril do ano de 2020 (Figura 3). Entretanto, as investigações ocorreram, em sua maioria, entre janeiro a março de 2020. A maior incidência de publicações foi no mês de março (53\%). A maioria dos casos ocorreu no sexo feminino (54\%) e na faixa etária entre 15 e 88 anos.

Figura 3. Relação da quantidade de publicações dos países em cada mês.

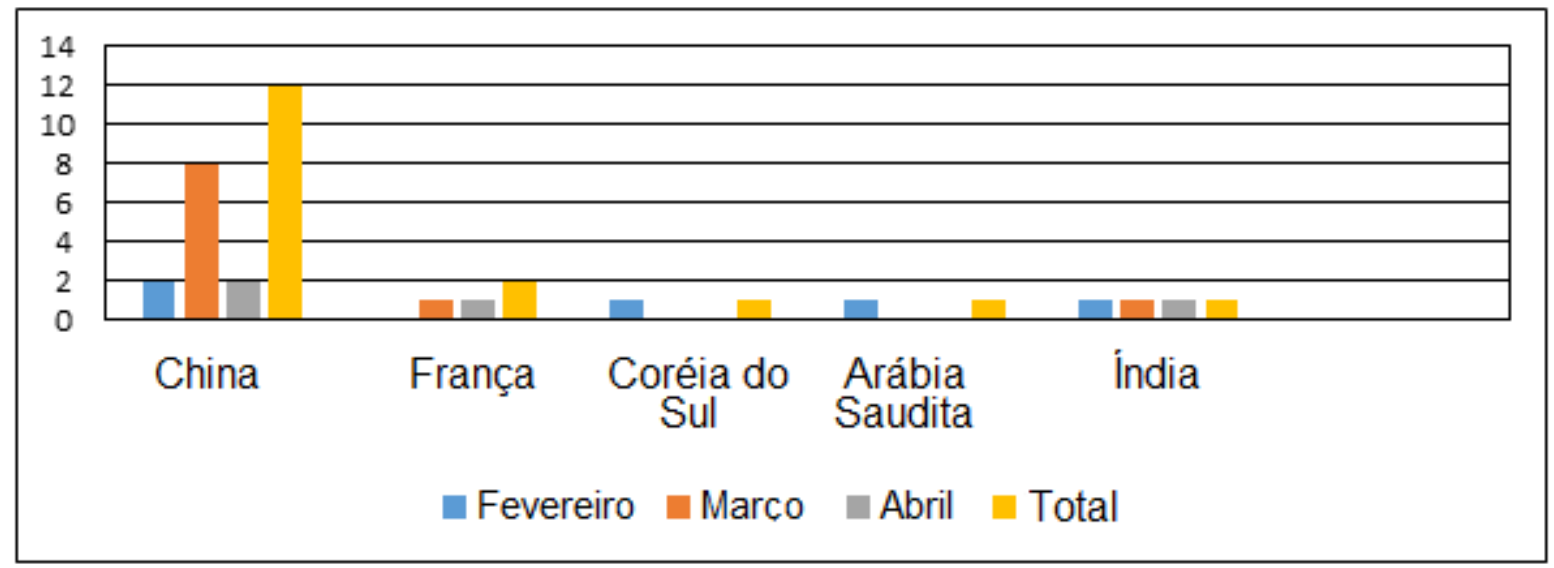

Fonte: Autores (2020).

Esta revisão sistemática envolveu diferentes desenhos de estudos (Tabela 2): in vitro (ID: 11), in silico (ID: 4, 12), ensaios clínicos abertos (ID: 1, 6, 7, 10 e 13), de coorte retrospectivo (ID: 3), controle randomizado (ID: 2), retrospectivos (ID: 8, 14, 15 e 16), analíticos (ID: 9) e observacional não controlado (ID: 5). Em três artigos, a amostra foi composta de apenas uma pessoa (ID: 7, 10 e 13), um teve quatro (ID: 14) e os demais apresentaram um número de casos entre 15 a 199 pacientes; destes, seis dividiram as amostras em dois grupos, utilizando um dos grupos para controle e/ou comparação (ID: 1, 2, 3, 5, 6 e 15). O período de estudo variou de 6 dias a 10 meses e 28 dias. A idade dos indivíduos estudados variou entre 18 a 91 anos. 
Tabela 2. Descrição dos artigos selecionados.

\begin{tabular}{|c|c|c|c|c|c|c|c|c|c|}
\hline \multirow[b]{2}{*}{ ID } & \multirow[b]{2}{*}{ Autor, país } & \multicolumn{3}{|c|}{ Dados bibliométricos } & \multirow[b]{2}{*}{ Tipo do estudo } & \multirow[b]{2}{*}{$\begin{array}{l}\text { Casos } \\
(\mathrm{n})\end{array}$} & Idade & \multicolumn{2}{|c|}{ Sexo } \\
\hline & & $\begin{array}{l}\text { Mês do } \\
\text { estudo }\end{array}$ & Local do estudo & $\begin{array}{l}\text { Período do } \\
\text { estudo }\end{array}$ & & & Min-max & $\begin{array}{l}\text { Masculino } \\
\mathrm{n}(\%)\end{array}$ & $\begin{array}{l}\text { Feminino } \\
\mathrm{n}(\%)\end{array}$ \\
\hline \multirow[t]{2}{*}{1} & \multirow{2}{*}{ Cai et al. (2020), China } & \multirow[t]{2}{*}{ Março } & \multirow{2}{*}{ The Third People's Hospital of Shenzhen } & \multirow[t]{2}{*}{14 dias } & \multirow[t]{2}{*}{ Ensaio clínico aberto } & 35 & $35-59$ & $14(40,0)$ & $21(60,0)$ \\
\hline & & & & & & 45 & $36-61$ & $21(46,7)$ & $24(53,4)$ \\
\hline \multirow[t]{2}{*}{2} & \multirow[t]{2}{*}{ Cao et al. (2020), China } & \multirow[t]{2}{*}{ Março } & \multirow[t]{2}{*}{ Jin Yin-Tan Hospital } & \multirow[t]{2}{*}{28 dias } & \multirow[t]{2}{*}{ Controle randomizado } & 100 & $49-68$ & $120(60,3)$ & $79(39,7)$ \\
\hline & & & & & & 99 & & & \\
\hline \multirow[t]{2}{*}{3} & \multirow[t]{2}{*}{ Deng et al. (2020), China } & \multirow[t]{2}{*}{ Março } & The Fifth Affiliated Hospital of Sun Yat-Sen & \multirow[t]{2}{*}{26 dias } & \multirow[t]{2}{*}{ Coorte retrospectivo } & 16 & $20-41$ & $7(52,0)$ & $9(48,0)$ \\
\hline & & & University & & & 17 & $25-47$ & $10(58,8)$ & $7(41,2)$ \\
\hline 4 & $\begin{array}{l}\text { Elfiky (2020), Arábia } \\
\text { Saudita }\end{array}$ & Fevereiro & $\mathrm{N} / \mathrm{E}$ & $\mathrm{N} / \mathrm{E}$ & In silico & N/A & N/A & N/A & N/A \\
\hline \multirow[t]{2}{*}{5} & \multirow[t]{2}{*}{ Gautret et al. (2020a), França } & \multirow[t]{2}{*}{ Março } & The Méditerranée Infection University Hospital & \multirow[t]{2}{*}{14 dias } & Observacional não & 26 & $18-51$ & $17(65,0)$ & $9(35,0)$ \\
\hline & & & Institute in Marseille & & controlado & 16 & $24-37$ & $6(37,0)$ & $10(63,0)$ \\
\hline 6 & Gautret et al. (2020b), França & Abril & $\begin{array}{l}\text { The Méditerranée Infection University Hospital } \\
\text { Institute in Marseille }\end{array}$ & 14 dias & Ensaio clínico aberto & $\begin{array}{l}77 \\
3\end{array}$ & $18-88$ & $43(53,8)$ & $37(46,2)$ \\
\hline 7 & $\begin{array}{l}\text { Lim et al. (2020), Coreia do } \\
\text { Sul }\end{array}$ & Fevereiro & Myongji Hospital & 8 dias & Ensaio clínico aberto & 1 & 54 & $1(100,0)$ & N/A \\
\hline 8 & Luo, Liu, Li. (2020), China & Março & Zhongfaxincheng Campus of Tongji Hospital & 8 dias & Retrospectivo & 15 & $62-80$ & $12(80,0)$ & $3(20,0)$ \\
\hline 10 & Ren et al. (2020), China & Março & $\mathrm{N} / \mathrm{E}$ & 6 dias & Ensaio clínico aberto & 1 & $\mathrm{~N} / \mathrm{E}$ & $1(100,0)$ & N/A \\
\hline 11 & Runfeng et al. (2020), China & Março & Laboratório de nível de biossegurança-3 & $\mathrm{N} / \mathrm{E}$ & In vitro & N/A & N/A & N/A & N/A \\
\hline 12 & Shah et al. (2020), Índia & Abril & $\begin{array}{l}\text { KB Institute of Pharmaceuticl Education and } \\
\text { Research }\end{array}$ & $\mathrm{N} / \mathrm{E}$ & In silico & N/A & N/A & N/A & N/A \\
\hline 13 & Shi et al. (2020), China & Abril & Guizhou Province People's Hospital & Fev-21-/05 & Ensaio clínico aberto & 1 & 50 & N/A & $1(100,0)$ \\
\hline 14 & Wang et al. (2020), China & Fevereiro & Shanghai Public Health Clinical Center & 15 dias & Retrospectivo & 4 & $19-63$ & $3(75,0)$ & $1(25,0)$ \\
\hline 15 & Zheng et al. (2020), China & Março & Cancer Center, Union Hospital & N/A & Retrospectivo & 34 & $29-77$ & $16(47,1)$ & $18(52,83)$ \\
\hline & & & & & & 21 & $29-91$ & $8(38,1)$ & $13(61,9)$ \\
\hline 16 & Zhu et al. (2020), China & Fevereiro & $\begin{array}{l}\text { Third People's Hospital of Changzhou and the } \\
\text { Second People's Hospital of Wuhu }\end{array}$ & 37 dias & Retrospectivo & 50 & 33 & $26(52,0)$ & $24(4,08)$ \\
\hline
\end{tabular}

ID: identificação dos artigos; min-max: mínimo-máximo; N/E: não especificado; N/A: não aplicado. Fonte: Autores (2020). 
Como a pandemia do COVID-19 começou na China, já era esperado que o maior número de estudos publicados (11), fossem desenvolvidos neste país. Entretanto, pode-se observar que apenas um dos artigos teve o tipo de estudo controle randomizado o que dificulta na comparação da eficácia da medicação, porém, quanto ao delineamento dos estudos, foi prevalente a metodologia de ensaios clínicos abertos (31\%). Em cinco estudos não foram especificados o período de estudos. A maioria das pessoas eram do sexo feminino (54\%) e faixa etária entre 15 a 88 anos.

Considerando os 16 estudos (Tabela 3), foram comparados diferentes regimes terapêuticos para tratamento de Covid19. Os esquemas terapêuticos comumente usados, listados em seis estudos (ID: 1, 2, 3, 7, 14 e 16), fizeram uso da combinação de lopinavir e ritonavir, sendo que, em três estudos, foi feita a combinação com arbidol (ID: 3, 14 e 16), em um usou favipiravir (ID: 1) e em outro com corticoide (ID: 3). Em dois estudos, foram utilizados hidroxicloroquina e azitromicina (ID: 5, 6). Os outros estudos relataram o uso de diferentes regimes terapêuticos - sofosbuvir, rivabirina, remidisvir, IDX-184, trifosfato de guanosina e trifosfato de uracilo (ID: 4); tocilizumab e corticóide (ID: 8); glicirrizina (ID: 9); medicina tradicional chinesa: fórmula Qingfei Paidu Decoction (QPD), oseltamivir e ganciclovir (ID: 10); medicina tradicional chinesa: fórmula LianhuaQingwen (LH) (ID: 11) e piperacilina-tazobactam, tratamento com troca plasmática intensiva, imunoglobulina intravenosa e metilprednisolona (ID: 15). 
Tabela 3. Tratamento recomendado para Covid-19.

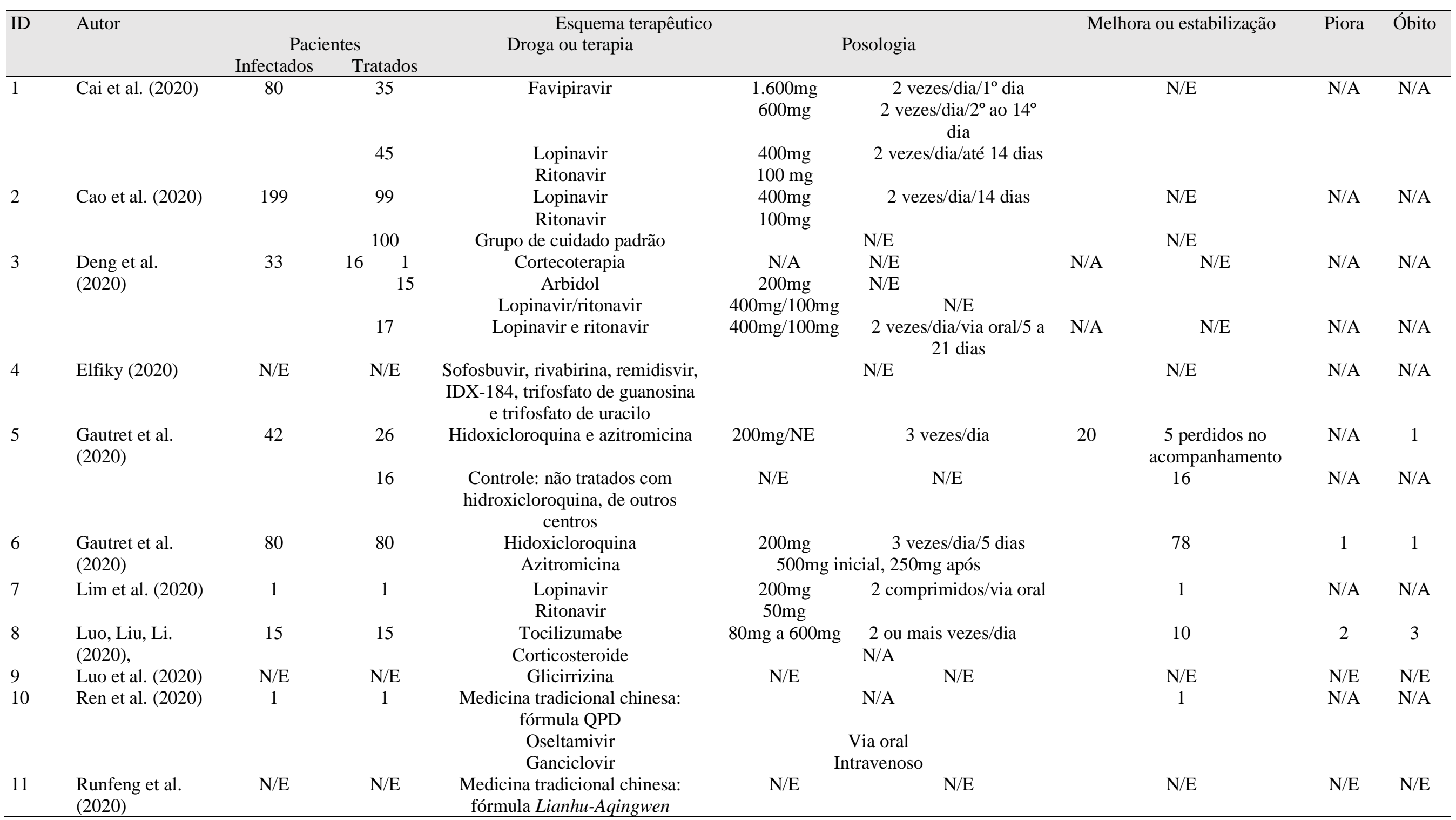


Research, Society and Development, v. 10, n. 1, e21310111533, 2021

(CC BY 4.0) | ISSN 2525-3409 | DOI: http://dx.doi.org/10.33448/rsd-v10i1.11533

\begin{tabular}{|c|c|c|c|c|c|c|c|c|c|c|}
\hline 12 & Shah et al. (2020) & $\mathrm{N} / \mathrm{E}$ & $\mathrm{N} / \mathrm{E}$ & $\begin{array}{c}\text { Antivirais utilizados em outras } \\
\text { patologias }\end{array}$ & \multicolumn{2}{|c|}{$\mathrm{N} / \mathrm{E}$} & \multicolumn{2}{|r|}{$\mathrm{N} / \mathrm{E}$} & $\mathrm{N} / \mathrm{E}$ & $\mathrm{N} / \mathrm{E}$ \\
\hline \multirow[t]{4}{*}{13} & Shi et al. (2020) & 1 & 1 & Piperacilina-tazobactam & $4,5 \mathrm{~g}$ & $\begin{array}{l}\text { 3vezes/dia/via } \\
\text { intravenosa }\end{array}$ & \multirow{4}{*}{\multicolumn{2}{|c|}{1}} & N/A & N/A \\
\hline & & & & $\begin{array}{l}\text { Tratamento com troca plasmática } \\
\text { intensiva }\end{array}$ & $\mathrm{N} / \mathrm{E}$ & $\mathrm{N} / \mathrm{E}$ & & & & \\
\hline & & & & Imunoglobulina intravenosa & $20 \mathrm{~g}$ & N/E & & & & \\
\hline & & & & Metilprednisolona & $80 \mathrm{mg}$ & $\mathrm{N} / \mathrm{E}$ & & & & \\
\hline 14 & $\begin{array}{l}\text { Wang et al. } \\
(2020)\end{array}$ & 4 & 4 & Lopinavir & \multicolumn{2}{|c|}{$400 \mathrm{mg}$} & \multicolumn{2}{|r|}{4} & $\mathrm{~N} / \mathrm{E}$ & $\mathrm{N} / \mathrm{E}$ \\
\hline 15 & $\begin{array}{l}\text { Zheng et al. } \\
(2020)\end{array}$ & 55 & 21 & Metilprednisolona & \multicolumn{2}{|c|}{$0,5 \mathrm{mg} / 5$ dias } & \multicolumn{2}{|r|}{55} & $\mathrm{~N} / \mathrm{E}$ & 13 \\
\hline \multirow[t]{2}{*}{16} & \multirow[t]{2}{*}{ Zhu et al. (2020) } & \multirow[t]{2}{*}{50} & 34 & $\begin{array}{l}\text { Lopinavir } \\
\text { Ritonavir }\end{array}$ & $\begin{array}{l}400 \mathrm{mg} \\
100 \mathrm{mg}\end{array}$ & & \multirow[t]{2}{*}{$\begin{array}{l}\text { Após } \\
7^{\circ} \text { dia }\end{array}$} & \multirow[t]{2}{*}{$\mathrm{N} / \mathrm{E}$} & \multirow{2}{*}{\multicolumn{2}{|c|}{$\begin{array}{c}23,5 \% \text { - carga } \\
\text { viral detectável } \\
\text { Carga viral } \\
\text { indetectável }\end{array}$}} \\
\hline & & & 16 & Arbidol & $0,2 \mathrm{~g}$ & 3 vezes/dia & & & & \\
\hline
\end{tabular}

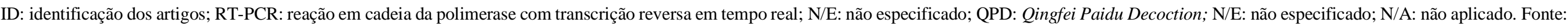
Autores (2020). 
Diante de tamanha proporção de óbitos registrados, seria muito importante que todos os estudos tivessem registrado o número de pacientes que evoluíram para a cura, estabilização ou óbito. É possível observar que os critérios de melhora e estabilização não foi descrito pela maioria dos autores.

Em relação à melhora ou à estabilização e a óbitos, apenas nove estudos informaram o número de pacientes tratados (ID: 3, 5, 6, 7, 8, 13, 14, 15 e 16) e, destes, três informaram a ocorrência de óbitos (ID: 5, 6 e 8).

Somente dois estudos informaram sobre os critérios de melhora ou estabilização, os quais usaram como critério RTPCR negativo após 7 dias de tratamento (ID: 3) e carga viral indetectável após 7 dias de tratamento (ID: 16). A eficácia do tratamento foi avaliada mediante capacidade de inativação do vírus, remissão dos sinais e sintomas da Covid-19 e diminuição da carga viral, de acordo com o quadro 2, na qual podem-se encontrar as conclusões dos estudos de acordo a terapia investigada (Tabela 3).

Em 6 estudos foram utilizados como terapia medicamentosa, a combinação entre lopinavir/ritonavir. Entretanto, não houve consenso entre os autores em relação aos resultados, especialmente em estudos onde foram utilizadas outras drogas como coadjuvantes, em que afirmam ter tido melhor resultado com a outra droga em relação a lopinavir/ritonavir. Já outros autores descreveram resultados positivos com a combinação do lopinavir/ritonavir e outras drogas (Tabela 4). 
Tabela 4. Conclusão dos estudos de acordo à terapia utilizada.

Autor

Conclusão do estudo

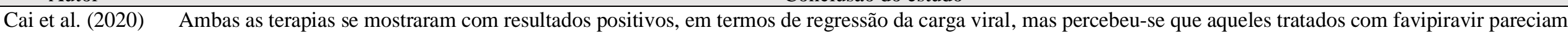
ter depuração viral mais rápida e melhor alteração na imagem do tórax do que os tratados com lopinavir/ritonavir

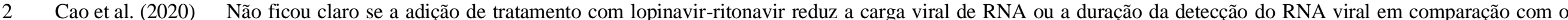
tratamento de suporte padrão isolado. Não foram encontradas evidências significativas do medicamento. Além disso, o perfil de efeitos colaterais observado desperta preocupação com o uso de regimes de doses mais altas ou mais prolongadas de lopinavir/ritonavir nos esforços para melhorar os resultados

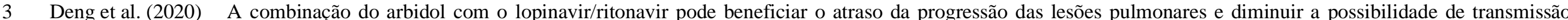
respiratória e gastrintestinal, por diminuir a carga viral da Covid-19 e conter alta concentração fecal. Ainda são necessários estudos prospectivos e randomizados, e o mecanismo de seu efeito antiviral para o coronavírus permanece incerto

$4 \quad$ Elfiky $(2020)$

Os medicamentos IDX-184, sofosbuvir, remdisivir e ribavirina tiveram resultados promissores contra a nova cepa do coronavírus, provando forte ligação com a RdRp, contradizendo a função dessa enzima e, consequentemente, impedindo a replicação viral. Destaca-se que o IDX-184 mostra-se mais eficaz que o sofosbuvir na inibição do vírus, sugerindo uma associação dos dois para otimizar os resultados. Derivados de Trifosfato de Guanosina podem ser utilizados como inibidores específicos contra a Covid-19

5 Gautret et al. (2020) A hidroxicloroquina esteve significantemente associada à redução/ao desaparecimento da carga viral, e seu efeito foi reforçado pela azitromicina

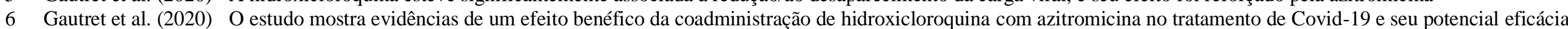
na redução precoce da contagiosidade

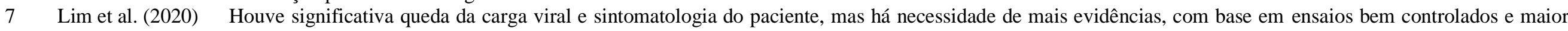
número de amostras

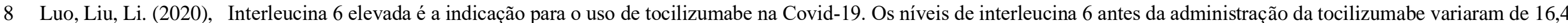
a $627,1 \mathrm{pg} / \mathrm{mL}$ ( 2 vezes a quase 90 vezes mais que o normal). Após o início da terapia com tocilizumabe, o nível sérico de interleucina 6 em 10 (66,7\%) pacientes tendeu a aumentar rapidamente logo no início e depois diminuiu. Um paciente demonstrou diminuição persistente da interleucina 6 após a administração de tocilizumabe combinada com metilprednisolona. Os pacientes estudados tinham a doença moderada ou grave. Alguns pacientes gravemente enfermos foram a óbito, e neles foi observado aumento persistente e dramático da interleucina 6

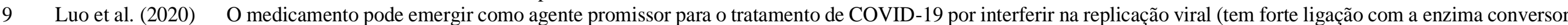
de angiotensina II, impedindo a penetração viral) e também diminuindo a patogenicidade, como antiviral e inibidor seletivo de trombina (evitando e ou diminuindo a tempestade de citocinas). Porém como foram realizados apenas estudos in vitro, efeitos colaterais e doses, além de considerações pré-patológicas, devem ser avaliados

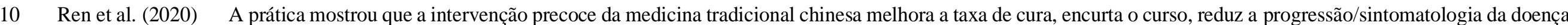
e reduz a taxa de mortalidade

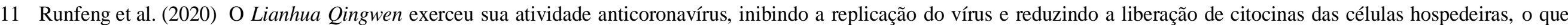
apoiou sua aplicação clínica em combinação com as terapias existentes para tratar a Covid-2019

12 Shah et al. (2020)

Os quatro inibidores da enzima protease (lopinavir, asunaprevir, indinavir e ritonavir) demonstraram utilidade no combate ao vírus que depende da proteína. Além disso, um tratamento medicamentoso para a hepatite C, o paritaprevir (ABT450), é um candidato útil para o combate ao coronavírus

13 Shi et al. (2020)

O início oportuno do tratamento com troca de plasma seguido de imunoglobulina intravenosa em pacientes gravemente enfermos com Covid-19 pode impedir que a doença se agrave e ajudar a reduzir os requisitos de ventilação mecânica e cuidados intensivos. Além disso, pode melhorar os resultados clínicos ruins desses pacientes. Este tratamento de combinação perfeita produziu efeito satisfatório, pois conteve a tempestade de citocinas, que pode ser o centro da fisiopatologia da infecção fatal pelo vírus. Ensaios clínicos randomizados são urgentemente necessários para confirmar a eficácia da troca de plasma combinada com imunoglobulina intravenosa em pacientes com Covid-19 em estado crítico 


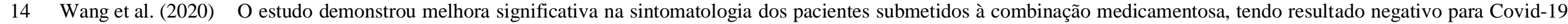
em $50 \%$ deles após o tratamento. No entanto, mais pesquisas merecem ser realizadas

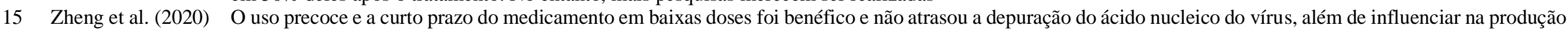
de anticorpos IgG. No entanto, são necessárias estratégias de observações contínuas para avaliação dessa estratégia adaptada ao risco

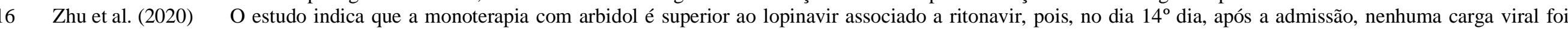
detectada no grupo arbidol, mas carga viral foi encontrada em 44,1\% dos pacientes tratados com lopinavir/ritonavir. Nenhum efeito colateral aparente foi encontrado nos dois grupos. A principal limitação desse estudo é o tamanho da amostra, não concluindo a real eficiência dos medicamentos para cura, apenas identificando o que teve melhor resultado, no caso, o arbidol.

RdRp: RNA-dependent RNA polymerase. Fonte: Autores (2020). 
Em um estudo, os autores descreveram resultados promissores contra a nova cepa do coronavírus com a combinação de IDX-184, sofosbuvir, remdisivir e ribavirina. Resultados significativos com a combinação entre hidroxicloroquina e azitromicina, da mesma forma a administração de tocilizumabe combinada com metilprednisolona. A medicina tradicional chinesa auxiliou na melhora da taxa de cura e redução da taxa de mortalidade. Em combinação com as terapias existentes para tratar a COVID-19, o Lianhua Qingwen inibiu a replicação viral. Também relatado o uso da troca de plasma seguido de imunoglobulina intravenosa, pode impedir o agravamento da doença (Tabela 4)

\section{Discussão}

A maior quantidade de publicações concentrou-se na China, o que pode ser justificado pelo fato de lá ter sido o primeiro país a identificar o vírus e também por já ter experiências anteriores com o vírus. Em 2002, causou uma epidemia na província de Guangdong, na China (Lu et al., 2020; Zhou et al., 2020), espalhando-se por mais de 20 países, onde o vírus atingiu 8.098 pessoas, matando 774 delas e causando perda de quase US\$40 milhões em atividades econômicas (Fehr \& Perlman, 2015).

Os estudos analisados tiveram como base vírus já conhecidos e controlados ou doenças respiratórias causadas por eles, pois possuem grande similaridade na apresentação de sintomas, sinais e características genéticas e estruturais. Pode-se, assim, aprender com o uso de medicamentos já utilizados (Lim et al., 2020).

De acordo com os estudos encontrados, ainda não existe tratamento aprovado para a Covid-19. Medicamentos antivirais são estudados com intenção de combater a viremia, prevenindo a letalidade. Ensaios clínicos e estudos controlados mostraram que muitos são eficazes no alívio dos sintomas e na diminuição da carga viral (Li et al., 2020), assim como estudos in vitro e in silico probabilizam suas eficácias (Khamitov et al., 2020; Shah et al., 2020).

De acordo com Lim (2020b), o efeito da combinação lopinavir/ritonavir (200mg/50mg duas vezes ao dia) por 8 dias auxiliou na redução da carga viral, tendo RT-PCR negativo no oitavo dia de tratamento. Apesar de não ter comprovação da eficiência concreta da medicação, pelas limitações do estudo, pode-se observar que a combinação de lopinavir/ritonavir, inibiu a protease, enzima necessária para replicação viral (Perlman \& Netland, 2009), impedindo a conclusão do ciclo e, consequentemente, diminuindo a quantidade de vírus no organismo.

No entanto, Cao et al. (2020), não encontraram efeitos parecidos da combinação lopinavir/ritonavir em estudo de coorte controlado, que avaliou um grupo de pacientes que fizeram uso de tratamento e suporte padrão e outro grupo que fazia uso de lopinavir/ritonavir (400mg/100mg) duas vezes ao dia isoladamente, comparando-os. O acompanhamento se deu por 28 dias. Não foram encontradas eficácias na diminuição da quantidade de carga viral dos pacientes do grupo lopinavir/ritonavir, mas demonstraram-se preocupações em relação aos efeitos adversos observados durante o tratamento, ainda que tenham sido apontadas diferença no número de mortes entre os grupos (19,2\% versus $25,0 \%)$, com o menor percentil para o grupo utilizando lopinavir/ritonavir. O controle e a quantidade de amostras do estudo são diferentes. $\mathrm{O}$ uso dos medicamentos por 8 dias não deve manifestar efeitos colaterais como em um tratamento mais longo de 28 dias e com o dobro de miligramas, sujeitando à diferença de resultados.

Outros estudos foram realizados com a utilização do lopinavir/ritonavir, porém com outras combinações. Zhu et al. (2020) analisaram 50 pacientes, divididos em dois grupos: 16 para fazer uso de arbidol (0,2mg, três vezes ao dia, por 1 semana) e 34 pacientes fazendo uso de lopinavir/ritonavir (400mg/100mg, duas vezes ao dia, por 1 semana). Apesar de o tratamento durar 1 semana, o estudo continuou por cerca de 15 dias com a avaliação dos pacientes submetidos nos dois grupos. Nenhum efeito colateral foi encontrado em ambos os grupos. Não houve tantas diferenças entre um grupo e outro em relação à sintomatologia e em exames laboratoriais e de imagem, apesar de ambos apresentarem melhoras. No entanto, no $14^{\circ}$ dia do estudo, $100 \%$ dos pacientes do grupo arbidol apresentaram RT-PCR negativo, enquanto esse resultado foi de 55,9\% para o grupo lopinavir/ritonavir, concluindo que a monoterapia com arbidol é mais eficaz para a Covid-19 que lopinavir/ritonavir. 
O arbidol é um antiviral de amplo espectro utilizado no tratamento e na profilaxia de influenzas, por impedir a patogenicidade do vírus, evitando a replicação viral e impedindo a infecção de outras células. Possui atividades imunomoduladoras, antioxidantes e indutoras de interferon (IFN) (Boriskin et al., 2008), o que justifica o resultado do estudo.

Estudos semelhantes fizeram a divisão em dois grupos e comparam quanto aos resultados (Deng et al., 2020; Zhu et al., 2020). Um deles, com 33 pacientes, formou um grupo de 16 pacientes para fazer uso de terapia combinada de arbidol 200mg a cada 4 horas + lopinavir/ritonavir 400mg/100mg a cada 12 horas e outro com 17 pacientes para fazer uso de lopinavir/ritonvir $400 \mathrm{mg} / 100 \mathrm{mg}$ a cada 12 horas. O tratamento aconteceu até o paciente negativar para RT-PCR, o que variou de 5 a 21 dias. O grupo de terapia combinada obteve maior sucesso, ainda que não muito significativo, comparado ao monoterápico, confirmando os achados em outros estudos, que avaliaram a eficiência das duas medicações isoladamente (Cao et al., 2020; Lim et al., 2020; Zhu et al., 2020).

Por sua vez, Wang et al. (2020) associaram lopinavir/ritonavir ao arbidol e a uma receita da medicina tradicional chinesa, a cápsula de Shufeng Jiedu (SJDC). O estudo avaliou quatro casos, de moderado a grave, seguindo a terapia lopinavir/ritonavir (400mg/100mg) duas vezes ao dia + arbidol 0,2g uma vez ao dia + SJDC 2,8g uma vez ao dia. O tratamento variou de 6 a 15 dias, dependendo da resposta de cada caso. A associação medicamentosa teve grande relevância nos pacientes estudados, obtendo aumento de linfócitos e leucócitos em todos eles, restaurando a função imunológica. A TC de tórax apresentou melhoras em todos os casos (variando a qualidade em cada um) e dois dos totais de casos negativaram amostras de swab coletadas do trato respiratório superior até o terceiro dia de tratamento. Esse sucesso deve-se à característica antiviral de liponavir/ritonavir adicionada à composição de ervas na receita SJDC, que garantem fortalecer o sistema imunológico e auxiliar na recuperação do tecido pulmonar (Wang et al., 2020) e à característica antiviral, imunomoduladora e antioxidante do arbidol (Boriskin et al., 2008).

O uso da medicina tradicional chinesa também foi discutido e experimentado em estudo em que foi utilizada a fórmula QPD (Ren et al., 2020) e a fórmula LH (Runfeng et al., 2020), obtendo como resultados efeitos antitérmicos e antivirais em ambas (em especial na LH, considerada de amplo espectro), melhorando os sintomas da SARS-CoV-2. A LH destacou-se no estudo como reguladora imunológica, por reduzir a interleucina 6 (IL-6) e melhorar o quadro de pacientes considerados graves. Essas terapias, fazem parte das diretrizes chinesas de tratamento para COVID-19.

Em estudo controlado aberto teve amostra de 80 pessoas, divididas em grupos, sendo um com 35 pacientes que fizeram uso de favipiravir $200 \mathrm{mg}$ obedecendo a terapia de primeiro dia com $1.600 \mathrm{mg}$ e segundo dia ao $14^{\circ} \mathrm{com} 600 \mathrm{mg}$, e outro com 45 pacientes que fizeram uso de lopinavir $400 \mathrm{mg} /$ ritonavir $100 \mathrm{mg}$ duas vezes ao dia. $\mathrm{O}$ tratamento durou até o resultado negativo da RT-PCR, que variou de 2 a 14 dias. O favipiravir demostrou maior depuração da carga viral e em menos tempo, comparada ao lopinavir/ritonavir (Cai et al., 2020). A favipiravir é uma droga inibidora da RNA-dependent RNA polymerase (RdRp) que demonstrou ser eficaz no tratamento do vírus Ébola (Oestereich et al., 2014). A RdRp é uma enzima crucial na replicação do SARS-CoV-2 (Mcintosh \& Bloom, 2020; Singhal, 2020). Percebeu-se que ambos os medicamentos agem em enzimas necessárias para a replicação viral, explicando a pouca diferenciação dos resultados, e esses medicamentos conseguem diminuir a carga viral.

Foi realizada uma pesquisa que avaliou 15 pacientes que apresentavam quadro clínico de grave a moderado sobre o uso de tocilizumabe, com dosagem de 80 a 600mg por dia, dependendo da gravidade do paciente. O medicamento mostrou eficiência no grupo pesquisado reduzindo quadros graves e tornando assintomáticos quadros moderados (Luo et al., 2020). O tocilizumabe é um anticorpo monoclonal humanizado contra o receptor da interleucina-6 (IL-6R), já recomendado em pacientes gravemente enfermos com IL-6 elevada pela Comissão Nacional de Saúde da China. O estudo pode ser considerado de grande eficácia, já que os pacientes que sofrem de tempestades de citocinas progridem para colapso cardiovascular, disfunção de múltiplos órgãos e evoluem para óbito (Sarzi-Puttini et al., 2020). 
Outra terapia utilizada como promissora contra o coronavírus é a glicirrizina. Concluiu-se que, além de reguladora de citocinas, ela também inibe a enzima conversora da angiotensina 2, receptora do SARS-CoV-2 em células humanas (Luo et al., 2020). O uso de costicoteroides também é discutido em casos de agravamento dos sintomas na infecção por coronavírus, como a síndrome respiratória aguda grave (SARS) (Singhal, 2020) e a síndrome respiratória do Oriente Médio (MERS) (Arabi et al., 2018). Utilizando-se a metilprednisolona, que é um glucocorticoide com atividade anti-inflamatória, descobriu-se que, em casos de grande ativação da cascata de citocinas (IL-6), o medicamento teve efeito benéfico. No entanto, percebeu-se que, com altas doses de corticoides, são provocados efeitos imunossupressores, mas que, em baixas doses e a curto prazo, reduz-se significativamente a gravidade da Covid-19 e estimula-se a produção de anticorpos IgG (Zheng et al., 2020).

Em estudo feito com caso clínico grave que não respondia à terapia convencional, obteve-se bom prognóstico com a utilização de troca plasmática intensiva, seguida de imunoglobulina intravenosa com três a quatro sessões seguidas, acompanhado por período de 23 dias. O caso apresentou melhora nos sintomas após a terceira sessão: aumento da saturação de oxigênio em ar ambiente, restauração da pressão arterial e evidências radiográficas melhoradas. Após a quarta sessão, não apresentava sintomas, e a RT-PCR foi negativa (Shi et al., 2020). Por meio de estudo in silico, Sha et al. utilizaram 37 moléculas de medicamentos antivirais com eficácia comprovada em outras patologias causada por vírus, como hepatite C, Ébola, influenzas e outras, e as acoplaram a uma enzima-alvo da Covid-19 (Shah et al., 2020).

Os medicamentos lopinavir, asunaprevir, remdisivir, ligantes seletivos dos receptores de angiotensina AT1 e AT2 (CGP42112A), indinavir, ritonavir, aritaprevir, marboran (methisazone) e galidesivir interagiram com mais de uma estrutura da enzima, tornando-os candidatos a promissores contra a SARS-CoV-2. O estudo demonstra concordância com estudos in vivo, quanto à eficácia desses medicamentos (Deng et al., 2020; Lim et al., 2020; Wang et al., 2020; Zhu et al., 2020). Elfiky acoplou a enzima RdRp e preparou moléculas de medicamentos antivirais, com o intuito de compará-las quanto à maior ligação à enzima. As moléculas medicamentosas foram de sofosbuvir, ribavirina, cinamaldeído e timoquinona, e sofosbuvir, ribavirin e remdisivir foram fortes ligantes, caracterizados como inibidores eficientes da RdRp, demonstrando possível utilidade contra a SARS-CoV2 (Elfiky, 2020). Em ensaio com a utilização de células-tronco mesenquimais menstruais, com o objetivo de saber a eficiência delas no controle de lesões pulmonares, devido às características de autorrenovação dessas células, foi feita a comparação entre a influenza (H7N9) e a Covid-19, devido à similaridade encontrada nos vírus e os achados clínicos (Chen et al., 2020). O estudo mostrou resultados positivos, mas não comprovou maiores benefícios das células-tronco mesenquimais comparadas ao uso de outros antivirais na melhora da SARS. Gautret et al. realizaram dois estudos utilizando o fosfato de hidroxicloroquina para avaliação da diminuição da carga viral e sintomas na Covid-19. No primeiro, em março, foi utilizada a hidroxicloroquina (200mg) isolada, utilizando a azitromicina $(500 \mathrm{mg})$ em pacientes que apresentavam quadro clínico grave, obtendo resultados positivos (Gautret et al., 2020a). No segundo, em abril, a azitromicina $(500 \mathrm{mg}$ ) foi adicionada na terapia de forma combinada à hidroxocloroquina (200mg) (Gautret et al., 2020b). Concluiu-se, em ambos os estudos, que a hidroxocloroquina e a azitromicina podem tratar a doença e limitar a transmissão da infecção viral de pessoa para a pessoa.

Dentre as limitações encontradas para realizar essa revisão, destaca-se o número limitado de estudos encontrados durante o período de estudo que apresentassem dados estatísticos satisfatórios relativos ao tratamento da COVID-19, possibilitando a realização de metanálise, como dados relativos às razões de chance. Desta forma, sugere-se realização de mais estudos randomizados, de acordo com as recomendações Consolidated Standards of Reporting Trials (CONSORT), incluindo esquema terapêutico com os dados completos, cura, mortes, acompanhamento. Para a avaliação da resposta clínica diante dos diferentes protocolos terapêuticos, a compilação desses dados contribuiria de forma substancial. 


\section{Conclusão}

A terapia mais estudada entre os artigos foi a associação lopinavir/ritonavir, utilizada em sete artigos diferentes, seguida do arbidol (quatro artigos), medicina tradicional Chinesa (dois artigos) e hidroxicloroquina + azitromicina (dois artigos). Foram encontradas divergências em resultados com mesma terapia, que podem ser evidenciados pela abordagem de diferentes estudos. A maior parte dos medicamentos estudados já faz parte de protocolos para tratamento da Covid-19 em alguns países, como, por exemplo, a China, em seu protocolo versão 7. Porém a intenção dos estudos é obter evidências de qual o tratamento ideal para os casos, melhorando a assistência aos doentes, para aumentar as taxas de cura e, principalmente, evitar que adoeçam. Esses estudos analisados denotam que a SARS-CoV-2 é uma doença pandêmica e complexa, acometendo especialmente o sexo feminino, e que tem se expandido para o mundo inteiro. Seu tratamento ainda é um desafio para a saúde pública devido à ampla evolução, à adaptação e à disseminação do vírus.

Diante do exposto é de suma importância que sejam desenvolvidas mais pesquisas, com delineamento randomizado, que apresentassem dados estatísticos satisfatórios relativos ao tratamento da COVID-19, dando subsídios para realizar metanálise, elucidando assim algumas ambiguidades e polêmicas que pairam no meio científico sobre a temática.

\section{Referências}

Arabi, Y. M., Mandourah, Y., Al-Hameed, F., Sindi, A. A., Almekhlafi, G. A., Hussein, M. A., Jose, J., Pinto, R., Al-Omari, A., Kharaba, A., Almotairi, A., Al Khatib, K., Alraddadi, B., Shalhoub, S., Abdulmomen, A., Qushmaq, I., Mady, A., Solaiman, O., Al-Aithan, A. M., Fowler, R. A., the Saudi Critical Care Trial Group (2018). Corticosteroid therapy for critically ill patients with middle east respiratory syndrome. American Journal of Respiratory and Critical Care Medicine, 197(6), 757-767.

Boriskin, Y., Leneva, I., Pecheur, E. I., \& Polyak, S. (2008). Arbidol: a broad-spectrum antiviral compound that blocks viral fusion. Current Medicinal Chemistry, 15(10), 997-1005.

Brasil. Ministério da Saúde. (2020). Diretrizes para diagnóstico e tratamento da COVID-19 (Vol. 4). Brasília, DF: Ministério da Saúde. https://portalarquivos.saude.gov.br/images/pdf/2020/May/08/Diretriz-Covid19-v4-07-05.20h05m.pdf

Cai, Q., Yang, M., Liu, D., Chen, J., Shu, D., Xia, J., Liao, X., Gu, Y., Cai, Q., Yang, Y., Shen, C., Li, X., Peng, L., Huang, D., Zhang, J., Zhang, S., Wang, F., Liu, J., Chen, L., Chen, S., \& Liu, L. (2020). Experimental treatment with favipiravir for COVID-19: an open-label control study. Engineering, 6(10); 4-10.

Cao, B., Wang, Y., Wen, D., Liu, W., Wang, J., Fan, G., Ruan, L., Song, B., Cai, Y., Wei, M., Li, X., Xia, J., Chen, N., Xiang, J., Yu, T., Bai, T., Xie, X., Zhang, L., Li, C., Yuan, Y., \& Wang, D. Z. C. (2020). A lopinavir-ritonavir trial in adults hospitalized with severe Covid-19. The New England Journal of Medicine, 382(19), 1787-1799.

Cespedes, M. da S., \& Souza, J. C. (2020). SARS-CoV-2: uma revisão para o clínico. SciELO Preprints, 1(1), 1-17.

Chan, K. W., Wong, V. T., \& Tang, S. C. W. (2020). COVID-19: An update on the epidemiological, clinical, preventive and therapeutic evidence and guidelines of integrative Chinese-Western medicine for the management of 2019 novel coronavirus disease. The American Journal of Chinese Medicine, 48(3), 737-762.

Chen, J., Hu, C., Chen, L., Tang, L., Zhu, Y., Xu, X., Chen, L., Gao, H., Lu, X., Yu, L., Dai, X., Xiang, C., \& Li, L. (2020). Clinical study of mesenchymal stem cell treatment for acute respiratory distress syndrome induced by epidemic influenza A (H7N9) infection: a hint for COVID-19 treatment. Engineering, 6(10), 1153-1161.

Deng, L., Li, C., Zeng, Q., Liu, X., Li, X., Zhang, H., Hong, Z., \& Xia, J. (2020). Arbidol combined with LPV/r versus LPV/r alone against Corona Virus Disease 2019: A retrospective cohort study. Journal of Infection, 81(1), e1-e5.

Elfiky, A. A. (2020). Anti-HCV, nucleotide inhibitors, repurposing against COVID-19. Life Sciences, $248,117477$.

Epidemiology Working Group for NCIP Epidemic Response, C. C. for D. C. and P. (2020). [The epidemiological characteristics of an outbreak of 2019 novel coronavirus diseases (COVID-19) in China]. Zhonghua Liu Xing Bing Xue Za Zhi, 41(2), 145-151.

Fehr, A. R., \& Perlman, S. (2015). Coronaviruses: an overview of their replication and pathogenesis. In H. J. Maier, E. Bickerton, \& P. Britton (Eds.), Coronaviruses: methods and protocols (Vol. 1282, Issue 1). Springer.

Galvão, T. F., Pansani, T. de S. A., \& Harrad, D. (2015). Principais itens para relatar Revisões sistemáticas e meta-análises: a recomendação PRISMA. Epidemiologia e Serviços de Saúde, 24(2), 335-342.

Gautret, P., Lagier, J. C., Parola, P., Hoang, V. T., Meddeb, L., Mailhe, M., Doudier, B., Courjon, J., Giordanengo, V., Vieira, V. E., Tissot Dupont, H., Honoré, S., Colson, P., Chabrière, E., La Scola, B., Rolain, J. M., Brouqui, P., \& Raoult, D. (2020a). Hydroxychloroquine and azithromycin as a treatment of COVID19: results of an open-label non-randomized clinical trial. International Journal of Antimicrobial Agents, $56(1), 105949$.

Gautret, P., Lagier, J., Parola, P., Hoang, V. T., Meddeb, L., Mailhe, M., Doudier, B., Courjon, J., Giordanengo, V., Vieira, V. E., Tissot Dupont, H., Honoré, S., Colson, P., Chabrière, E., La Scola, B., Rolain, J., Brouqui, P., \& Raoult, D. (2020b). Hydroxychloroquine and azithromycin as a treatment of COVID-19: results of an open-label non-randomized clinical trial. International Journal of Antimicrobial Agents, 56(1), 105949. 
Gorbalenya, A., Baker, S., Baric, R., de Groot, R., Drosten, C., Gulyaeva, A., Haagmans, B., Lauber, C., Leontovich, A., Neuman, B., Penzar, D., Perlman, S., Poon, L., Samborskiy, D., Sidorov, I., Sola, I., \& Ziebuhr, J. (2020). Severe acute respiratory syndrome-related coronavirus : The species and its viruses - a statement of the Coronavirus Study Group. Nature Microbiology. https://www.biorxiv.org/content/10.1101/2020.02.07.937862v1

Guo, Y. R., Cao, Q. D., Hong, Z. S., Tan, Y. Y., Chen, S. D., Jin, H. J., Tan, K. S., Wang, D. Y., \& Yan, Y. (2020). The orig in, transmission and clinical therapies on coronavirus disease 2019 (COVID-19) outbreak - an update on the status. Military Medical Research, $7(1), 11$.

Karami, P., Naghavi, M., Feyzi, A., Aghamohammadi, M., Novin, M. S., Mobaien, A., Qorbanisani, M., Karami, A., \& Norooznezhad, A. H. (2020). Mortality of a pregnant patient diagnosed with COVID-19: A case report with clinical, radiological, and histopathological findings. Travel Medicine and Infectious Disease, 101665.

Khamitov, R. A., Loginova, S. I., Shchukina, V. N., Borisevich, S. V, Maksimov, V. A., \& Shuster, A. M. (2020). Antiviral activity of arbidol and its derivatives against the pathogen of severe acute respiratory syndrome in the cell cultures. Voprosy Virusologii, 53(4), 9-13.

Li, X., Geng, M., Peng, Y., Meng, L., \& Lu, S. (2020). Molecular immune pathogenesis and diagnosis of COVID-19. Journal of Pharmaceutical Analysis, 10(2), $102-108$.

Lim, J., Jeon, S., Shin, H. Y., Kim, M. J., Seong, Y. M., Lee, W. J., Choe, K. W., Kang, Y. M., Lee, B., \& Park, S. J. (2020a). The author's response: case of the index patient who caused tertiary transmission of coronavirus disease 2019 in Korea: the application of lopinavir/ritonavir for the treatment of COVID-19 pneumonia monitored by quantitative RT-PCR. Journal of Korean Medical Science, 35(7), 1-6.

Lim, J., Jeon, S., Shin, H., Kim, M. J., Seong, Y. M., Lee, W. J., Choe, K., Kang, Y. M., Lee, B., \& Park, S. (2020b). Case of the index patient who caused tertiary transmission of coronavirus disease 2019 in Korea: the application of lopinavir/ritonavir for the treatment of COVID-19 pneumonia monitored by quantitative RT-PCR. Journal of Korean Medical Science, 35(6), 1-6.

Luo, P., Liu, D., \& Li, J. (2020). Pharmacological perspective: glycyrrhizin may be an efficacious therapeutic agent for COVID-19. International Journal of Antimicrobial Agents, 55(6), 105995.

Luo, P., Liu, Y., Qiu, L., Liu, X., Liu, D., \& Li, J. (2020). Tocilizumab treatment in COVID-19: A single center experience. Journal of medical virology, 92(7), 814-818.

Lu, S., Lin, J., Zhang, Z., Xiao, L., Jiang, Z., Chen, J., Hu, C., \& Luo, S. (2020). Alert for non-respiratory symptoms of Coronavirus Disease 2019 (COVID-19) patients in epidemic period: A case report of familial cluster with three asymptomatic COVID-19 patients. Journal of Medical Virology, 2019 , 1-4.

Mcintosh, K., \& Bloom, A. (2020). Doença de coronavírus 2019 (COVID-19). UpToDate, 2019. http://www.toledo.ufpr.br/portal/wpcontent/uploads/2020/04/Doença-por-coronv\%C3\%ADrus-2019-UPTODATE.pdf

Oestereich, L., Lüdtke, A., Wurr, S., Rieger, T., Muñoz-Fontela, C., \& Günther, S. (2014). Successful treatment of advanced Ebola virus infection with T-705 (favipiravir) in a small animal model. Antiviral Research, 105(1), 17-21.

Perlman, S., \& Netland, J. (2009). Coronaviruses post-SARS: update on replication and pathogenesis. Nature Reviews Microbiology, 7(6), 439-450. https://doi.org/10.1038/nrmicro2147

Pfefferle, S., Reucher, S., Nörz, D., \& Lütgehetmann, M. (2020). Evaluation of a quantitative RT-PCR assay for the detection of the emerging coronavirus SARS-CoV-2 using a high throughput system. Eurosurveillance, 25(9), 1-5.

Ramos, L. M. da C. de S., Faustino, M. V. de A. S., Silva, J. M. A. da, \& Freitas, G. R. M. de. (2020). O surto do novo coronavírus (2019-nCoV) e a COVID19. Paraíba: Centro de Informação de Medicamentos da Universidade Federal da Paraíba. https://www.ufpb.br/cim/contents/menu/publicacoes/cimforma/o-surtodo-novo-coronavirus-2019-ncov-e-a-covid19

Ren, J., Zhang, A. H., \& Wang, X. J. (2020). Traditional Chinese medicine for COVID-19 treatment. Pharmacological Research, $155($ January), 104743.

Runfeng, L., Yunlong, H., Jicheng, H., Weiqi, P., Qinhai, M., Yongxia, S., Chufang, L., Jin, Z., Zhenhua, J., Haiming, J., Ku i, Z., Shuxiang, H., Jun, D., Xiaobo, L., Xiaotao, H., Lin, W., Nanshan, Z., \& Zifeng, Y. (2020). Lianhuaqingwen exerts anti-viral and anti-inflammatory activity against novel coronavirus (SARSCoV-2). Pharmacological Research, 156, 104761.

Sarzi-Puttini, P., Giorgi, V., Sirotti, S., Marotto, D., Ardizzone, S., Rizzardini, G., Antinori, S., \& Galli, M. (2020). COVID-19, cytokines and immunosuppression: what can we learn from severe acute respiratory syndrome? Clinical and Experimental Rheumatology, 38(2), 337-342.

Shah, B., Modi, P., \& Sagar, S. R. (2020). In silico studies on therapeutic agents for COVID-19: Drug repurposing approach. Life Sciences, $252,117652$.

Shamseer, L., Moher, D., Clarke, M., Ghersi, D., Liberati, A., Petticrew, M., Shekelle, P., \& Stewart, L. A. (2015). Preferred reporting items for systematic review and meta-analysis protocols (PRISMA-P) 2015: elaboration and explanation. BMJ, 349(jan02 1), g7647-g7647.

Shi, H., Zhou, C., He, P., Huang, S., Duan, Y., Wang, X., Lin, K., Zhou, C., Zhang, X., \& Zha, Y. (2020). Successful treatment with plasma exchange followed by intravenous immunoglobulin in a critically ill patient with COVID-19. International Journal of Antimicrobial Agents, 56(2), 105974.

Singhal, T. (2020). Review on COVID19 disease so far. The Indian Journal of Pediatrics, 87(April), $281-286$.

Teixeira, M. Z. (2020). Protocolo de pesquisa clínica para avaliar a eficácia e a segurança de medicamento homeopático individualizado no tratamento e na prevenção da epidemia de COVID-19 TT - Clinical research protocol to evaluate the efficacy and safety of individualized home. Portal Regional da BVS, 62 . https://doi.org/10.13140/RG.2.2.26359.37281/3

Wang, Z., Chen, X., Lu, Y., Chen, F., \& Zhang, W. (2020). Clinical characteristics and therapeutic procedure for four cases with 2019 novel coronavirus pneumonia receiving combined Chinese and Western medicine treatment. BioScience Trends, 14(1), 64-68. 
Research, Society and Development, v. 10, n. 1, e21310111533, 2021 (CC BY 4.0) | ISSN 2525-3409 | DOI: http://dx.doi.org/10.33448/rsd-v10i1.11533

Zheng, C., Wang, J., Guo, H., Lu, Z., Ma, Y., Zhu, Y., Xia, D., Wang, Y., He, H., Zhou, J., Wang, Y., Fei, M., Yin, Y., Zheng, M., \& Xu, Y. (2020). Riskadapted Treatment Strategy For COVID-19 Patients. International Journal of Infectious Diseases, 94, 74-77.

Zhou, P., Yang, X. L., Wang, X. G., Hu, B., Zhang, L., Zhang, W., Si, H. R., Zhu, Y., Li, B., Huang, C. L., Chen, H. D., Chen, J., Luo, Y., Guo, H., Jiang, R. D., Liu, M. Q., Chen, Y., Shen, X. R., Wang, X., Zheng, X. S., \& Shi, Z. L. (2020). A pneumonia outbreak associated with a new coronavirus of probable bat origin. Nature, 579(7798), 270-273.

Zhu, Z., Lu, Z., Xu, T., Chen, C., Yang, G., Zha, T., Lu, J., \& Xue, Y. (2020). Arbidol monotherapy is superior to lopinavir/ritonavir in treating COVID-19. Journal of Infection, 81(1), e21-e23.

Zu, Z. Y., Jiang, M. D., Xu, P. P., Chen, W., Ni, Q. Q., Lu, G. M., \& Zhang, L. J. (2020). Coronavirus disease 2019 (COVID-19): A Perspective from China. Radiology, 296(2), E15-E25. 